\title{
Ocena zdolności do rozpoznawania zniekształconych bodźców słownych (podstawy teoretyczne, dostępne testy)
}

\section{The recognition of distorted speech assessment (theoretical framework and methods of assessment)}

\author{
Monika Lewandowska, Agnieszka Pluta, Agata Szkiełkowska, Henryk Skarżyński \\ Instytut Fizjologii i Patologii Słuchu, Światowe Centrum Słuchu, Warszawa/Kajetany \\ Adres autora: Monika Lewandowska, Światowe Centrum Słuchu, Naukowe Centrum Obrazowania \\ Biomedycznego, ul. Mokra 17, Kajetany, 05-830 Nadarzyn, e-mail: m.lewandowska@ifps.org.pl
}

\section{Streszczenie}

Zdolność do rozpoznawania zniekształconych bodźców słownych jest ważnym aspektem przetwarzania informacji słuchowej. Testy sprawdzające tę umiejętność powinny wchodzić w skład baterii przesiewowych czułych na wykrywanie ośrodkowych zaburzeń przetwarzania słuchowego (ang. Auditory Processing Disorder, APD).

\begin{abstract}
W prezentowanej pracy przedstawiono podstawy teoretyczne oraz wybrane testy do oceny zdolności do rozpoznawania mowy zniekształconej w wyniku filtracji częstotliwościowej, kompresji czasowej lub mowy prezentowanej w obecności sygnału zakłócającego.
\end{abstract}

Słowa kluczowe: mowa w hałasie • mowa filtrowana • mowa skompresowana • zrozumiałość mowy

Abstract

The ability to recognize degraded speech is an important aspect of auditory information processing. Therefore, the tests to check this ability should be included into screening batteries sensitive to the Auditory Processing Disorder (APD).

The paper presents a theoretical framework for the tests of the degraded speech (filtered speech, compressed speech and speech in noise) as well as some sample examinations.

Key words: speech in noise $\bullet$ filtered speech $\bullet$ compressed speech $\bullet$ speech intelligibility

\section{Wprowadzenie}

U dzieci w wieku szkolnym częstym objawem sugerującym wystąpienie uszkodzenia ośrodkowych procesów przetwarzania słuchowego (ang. Auditory Processing Disorders, APD) są trudności w rozumieniu złożonych poleceń, mowy wypowiadanej w szybkim tempie lub prezentowanej w hałasie czy w pomieszczeniach o dużym pogłosie (np. w klasie) [1,2]. Opisane wyżej problemy ze słuchowym przetwarzaniem materiału werbalnego mogą być rozpoznawane $\mathrm{w}$ wielu zaburzeniach neurorozwojowych, m.in. w dysleksji czy zespole nadpobudliwości psychoruchowej z deficytem uwagi [3].

Zgodnie z zaleceniami Amerykańskiej Akademii Audiologicznej [2] i Amerykańskiego Towarzystwa Mowy, Języka i Słuchu [1] w skład każdej baterii czułej na wykrywanie
APD powinny wchodzić testy zawierające materiał werbalny. Pozwalają one sprawdzić zdolność do przetwarzania mowy prezentowanej w obecności sygnału zakłócającego, wypowiadanej w szybkim tempie lub filtrowanej częstotliwościowo.

Na określenie procesów, które są mierzone przez ww. testy, $\mathrm{w}$ języku angielskim stosuje się powszechnie dwa terminy: 'understanding' („rozumienie”) i 'intelligibility' („zrozumiałość”). „Rozumienie” to m.in. „pojmowanie tego, co ktoś mówi”", a więc, żeby sprawdzić, czy ktoś „rozumie” prezentowany materiał słuchowy, nie wystarczy poprosić tę osobę o jego powtórzenie. Dlatego „rozumienie” mowy można badać raczej w odniesieniu do pełnych zdań i historii, gdy zadanie polega na ich odtworzeniu po uprzedniej ekspozycji. Z kolei „zrozumiały” oznacza m.in. „jasny”, „wyraźny”, a jednym z parametrów zrozumiałości

1. Definicje obu terminów pochodzą ze „Słownika języka polskiego PWN” z roku 2013. 
mowy jest stosunek sygnału do szumu, zwykle mierzony w testach, w których eksponowany jest materiał językowy na tle sygnału zakłócającego. Dlatego wydaje się, że bardziej adekwatnym terminem na określenie funkcji mierzonej w testach zawierających zniekształcone bodźce słowne jest właśnie „zrozumiałość”.

\section{Mózgowe korelaty percepcji mowy}

Każdy poziom obwodowego i ośrodkowego układu słuchowego jest zaangażowany w kodowanie dźwięków mowy, a więc również $\mathrm{w}$ proces jej odbioru. Uszkodzenie ślimaka, nerwu słuchowego czy pnia mózgu może powodować niższe wyniki w teście sprawdzającym zrozumiałość bodźców w hałasie. Materiał językowy u zdecydowanej większości osób praworęcznych, jak również u większości osób leworęcznych, jest opracowywany w korze lewej półkuli mózgu. Bodźce werbalne docierają do okolic pierwszorzędowych (41 i 42 pole wg Brodmanna), z których następnie trafiają do obszarów asocjacyjnych (pole 22). Lewy górny zakręt skroniowy jest mózgową reprezentacją słuchu fonematycznego i percepcji kategorialnej bodźców, a przednia część górnej bruzdy skroniowej silniej pobudza się w sytuacji, gdy prezentowany jest materiał zrozumiały niż niezrozumiały [4]. Z przedniej górnej bruzdy skroniowej informacje trafiają do kory przedczołowej oraz innych obszarów kory. Uszkodzenia wszystkich ww. struktur mogą powodować obniżony poziom wykonania zadań sprawdzających zrozumiałość mowy. Ponadto badania $\mathrm{z}$ zastosowaniem metod neuroobrazowania pokazują, że podczas zadania polegającego na wyodrębnianiu bodźców z szumu w tle pobudzają się takie struktury mózgu jak: lewy górny płacik ciemieniowy, kora ruchowa i przedruchowa oraz przednia część lewej górnej bruzdy skroniowej [5]. Uszkodzenie (wrodzone bądź nabyte) wszystkich wyżej wymienionych struktur mózgu może prowadzić do zaburzeń w zakresie rozumienia mowy zniekształconej bądź prezentowanej w obecności sygnału zakłócającego.

Poniżej zostaną przedstawione trzy podstawowe rodzaje testów mierzących „zrozumiałość” bodźców słownych, tj. 1) mowa prezentowana na tle hałasu/szumu, 2) mowa modyfikowana częstotliwościowo (filtrowana) oraz 3) mowa wypowiadana w szybkim tempie, skompresowana.

\section{Mowa w hałasie/szumie}

Zdolność do wyodrębnienia bodźca właściwego z tła jest procesem złożonym, kształtowanym na poziomie struktur podkorowych i korowych mózgu, w który zaangażowane są procesy uwagi, umiejętności interakcji międzyusznej, lokalizacji przestrzennej dźwięków i ich lateralizacji. Dlatego interpretując wyniki testów mierzących zrozumiałość mowy w obecności bodźców zakłócających, należałoby uwzględnić wszystkie ww. czynniki.

Typowa procedura badania polega na powtórzeniu przez osobę badaną zadanego słowa. Pomiar jest z reguły prowadzony oddzielnie dla każdego ucha. Wśród testów sprawdzających zrozumiałość mowy w szumie najbardziej powszechne są te wykorzystujące pojedyncze, z reguły jednosylabowe słowa (przykładową listę słów można znaleźć w tekście Wilsona i Burksa (2005) [6]. Słowa prezentowane są w różnym stosunku intensywności sygnału do szumu zakłócającego, czyli z różnym S/N (ang. Signal-to-Noise $R a$ tio, SNR), co oznacza, że mogą być podawane na tym samym poziomie intensywności $(\mathrm{S} / \mathrm{N}=0)$ ), być cichsze (ujemne wartości S/N) lub głośniejsze (dodatnie wartości $\mathrm{S} / \mathrm{N}$ ) niż szum. Sygnałem zakłócającym jest z reguły tzw. multitalker babble speech, czyli jednoczesna mowa wielu osób, często poddawana odpowiednim modyfikacjom, żeby wyrównać poziomy intensywności przekazów pochodzących od różnych mówców i zniekształcenia pojawiające się naturalnie w mowie spontanicznej. Na wyniki testów mierzących zrozumiałość mowy w szumie ma wpływ rodzaj bodźca dystrakcyjnego, co zostało pokazane w pracy Wilsona i wsp. (2007) [7]. W badaniach tych prezentowano słowa na tle równoczesnych przekazów pochodzących od wielu mówców albo szumu w paśmie mowy. U osób z normalnym słuchem wykonanie testu było o $2 \mathrm{~dB}$ lepsze w przypadku pierwszego $\mathrm{z}$ ww. warunków. Badaczy interesowała również kwestia, czy wyniki testu mierzącego zrozumiałość mowy są porównywalne $w$ dwóch sytuacjach eksperymentalnych: 1) kiedy intensywność dźwięków mowy jest stała a szumu tła zmienna lub odwrotnie, 2) gdy intensywność mowy jest zmienna, ale bodziec zakłócający podawany jest na tym samym poziomie [8]. Wyniki były tylko nieznacznie lepsze w sytuacji, gdy intensywność mowy się zmieniała, a szum pozostawał na stałym poziomie.

Próby mierzące zdolność rozumienia mowy w szumie można podzielić na procedury stałych wartości S/N (zdecydowana większość dostępnych testów) oraz te wykorzystujące algorytmy adaptacyjne. W pierwszej z ww. kategorii słowa są prezentowane na stałym poziomie intensywności względem szumu, a wynikiem testu jest liczba poprawnie powtórzonych słów przy zadanym $\mathrm{S} / \mathrm{N}$. Z kolei w procedurach adaptacyjnych, polegających na dostosowywaniu się wartości S/N do poziomu wykonania zadania przez osoby badane, wyznaczana jest wartość współczynnika S/N, przy której następuje poprawne powtórzenie 50\% zadanych słów. Jest to tzw. próg rozpoznawania mowy w szumie (ang. Speech Recognition Threshold in Noise, $\mathrm{SRT}_{\mathrm{N}}$ ).

Wśród procedur stałych wartości S/N na szczególną uwagę zasługuje Test słów w szumie (ang. Words-in-Noise, WIN) opracowany przez zespół R. Wilsona [9-12]. Test składa się z 3 list zawierających po 35 jednosylabowych słów prezentowanych do prawego lub lewego ucha. Szum podawano na stałym poziomie $70 \mathrm{~dB}$ SPL, a intensywność właściwych słów zmieniała się, dając $\mathrm{w}$ efekcie 7 różnych wartości współczynnika $\mathrm{S} / \mathrm{N}$, zawierających się w przedziale od $24 \mathrm{~dB}$ do $0 \mathrm{~dB}$ (w 4-decybelowych krokach). W rezultacie tych zabiegów poziom intensywności, na jakim prezentuje się słowa w teście, kształtuje się w granicach: 94-70 dB SPL. Wilson i współpracownicy do zestawu testów mierzących zrozumiałość mowy w szumie dołączyli również test sprawdzający, czy osoby badane potrafią powtórzyć poprawnie pojedyncze słowa prezentowane $\mathrm{w}$ ciszy, na komfortowym poziomie głośności $[7,13,14]$. Test posiada normy dla amerykańskich dzieci i dorosłych $[10,15]$. Wilson i wsp. [15] opublikowali m.in. wyniki badania testem WIN grupy 3000 weteranów wojennych. Udowodnili, że test jest rzetelną miarą zrozumiałości mowy w szumie oraz że rozpoznawanie dźwięków werbalnych w obecności sygnału zakłócającego lub w ciszy to odrębne procesy w ramach słuchowego przetwarzania informacji. 
Słowa ze stałą wartością $\mathrm{S} / \mathrm{N}$ są również prezentowane w testach tzw. słuchowej figury-tła (ang. Auditory Figure-Ground, AFG), wchodzących w skład amerykańskich baterii SCAN w wersji dla dzieci i dorosłych $[16,17]$. Nazwa testu nawiązuje do umiejętności wyodrębnienia $\mathrm{z}$ tła (szumu zakłócającego) sensownej całości, czyli figury (właściwego słowa). W wersji dla dorosłych (zawartej w baterii SCAN-A) jednosylabowe słowa są prezentowane $\mathrm{z} \mathrm{S} / \mathrm{N}=0 \mathrm{~dB}$ lub $\mathrm{S} / \mathrm{N}=4 \mathrm{~dB}$ w obecności sygnału zakłócającego, który stanowią równoczesne wypowiedzi kilku mówców. W wersji dla dzieci, włączonej do baterii SCAN-C, wykorzystywany jest ten sam materiał, tylko stosunek sygnału do szumu jest wyższy i wynosi $8 \mathrm{~dB}$. Bodźce prezentuje się oddzielnie do każdego ucha. Zadaniem osoby badanej jest powtórzenie każdego słowa bezpośrednio po jego ekspozycji. Obliczany jest procent poprawnych odpowiedzi udzielonych dla danego S/N.

Testy AFG zawierają materiał werbalny, dlatego oczywiste jest, że w wersji oryginalnej nie mogą być stosowane do oceny zrozumiałości mowy wypowiadanej w języku innym niż angielski. Okazuje się, że poziom wykonania tych testów różni się również między populacjami posługującymi się językiem angielskim: amerykańską i brytyjską [18]. Testem AFG przebadano 99 dzieci w wieku 6-10 lat, mieszkających w Wielkiej Brytanii, których językiem ojczystym był angielski. Dzieci brytyjskie radziły sobie znacząco gorzej w tym zadaniu niż ich amerykańscy rówieśnicy. Zdaniem autorów wyniki te wskazują na wpływ znajomości (bliskości) prezentowanego materiału oraz akcentu, z jakim były wypowiadane słowa, na wykonanie testu.

W wielu nieanglojęzycznych krajach, np. w Hiszpanii [19] czy Grecji [20], opracowano własne wersje językowe testu. Istnieje także wersja testu w języku hebrajskim [21] czy holenderskim [22,23]. W Holandii dostępny jest wystandaryzowany Test słów w hałasie (ang. Words in Noise Test $[22,23])$ zawierający jednosylabowe słowa prezentowane jednousznie. Sygnałem zakłócającym jest mowa o tej samej charakterystyce spektralnej co właściwe słowa, podawana do tego samego ucha co to słowo, na poziomie $65 \mathrm{~dB}$ SPL. Stosuje się dwie różne wartości S/N: $-2 \mathrm{i}-5 \mathrm{~dB}$. Właściwy test polega na prezentacji 4 list zawierających po 22 słowa, a kolejność list jest taka sama u każdej osoby badanej. Test poprzedzony jest sesją treningową (lista 12 słów, $\mathrm{S} / \mathrm{N}=0$ ). W teście oblicza się procent poprawnie powtórzonych słów oddzielnie dla każdej wartości współczynnika wyrażającego stosunek sygnału do szumu.

Również brytyjska bateria testów ośrodkowych procesów słuchowych (MAPA [24]) zawiera test zrozumiałości mowy $\mathrm{w}$ hałasie. Test zawiera jednosylabowe słowa eksponowane na tle równoczesnych wypowiedzi 4 mówców. Zdaniem autorów [24] test nie posiada satysfakcjonujących własności psychometrycznych (zwłaszcza rzetelność, szacowana metodą test-retest, jest niska) i może być stosowany tylko jako dodatkowa miara stopnia zrozumiałości bodźców słownych prezentowanych w hałasie.

W przypadku pomiaru stopnia zrozumiałości całych zdań najczęściej stosuje się procedury adaptacyjnej zmienności wartości S/N. Przykładowo Test zdań w hałasie (ang. Sentence-in-Noise Test) [23] mierzy $\mathrm{SRT}_{\mathrm{N}}$ dla zdań prezentowanych w obecności szumu zakłócającego. Zdania zawierają od 8 do 9 sylab, a słowa w zdaniach są jedno- lub dwusylabowe. Prezentuje się 3 zestawy po 13 zdań: pierwszy zestaw w ciszy, żeby zapoznać osobę badaną z materiałem bodźcowym, w drugim zestawie jako dźwięku zakłócającego używa się ciągłego szumu, a w ostatnim zestawie dystraktor ma postać zmiennego szumu. Zmienny szum włączono do materiału bodźcowego ze względu na możliwość dostarczenia informacji na temat możliwych deficytów przetwarzania czasowego u osób dorosłych z uszkodzonym słuchem obwodowym. Wcześniejsze badania wskazywały, że osoby te, w przeciwieństwie do dorosłych z prawidłową czułością słuchu, nie wypadały lepiej w sytuacji, gdy prezentowano szum zmienny, fluktuujący, w porównaniu $\mathrm{z}$ warunkiem $\mathrm{z}$ szumem stałym. W Teście zdań w hałasie bodźce prezentowane są tylko do prawego ucha. Zadanie polega na ich powtórzeniu. Szum jest podawany na stałym poziomie $65 \mathrm{~dB}$ SPL, a poziom intensywności zdań zmienia się w sposób adaptacyjny (o $2 \mathrm{~dB}$ ).

Innym przykładem może być Duński test zrozumiałości mowy (ang. Danish Speech Intelligibility Test [25]). Test składa się ze 180 zdań znajdujących się na 18 listach zbalansowanych pod względem fonetycznym. Poszczególne zdania są podobne pod względem zrozumiałości (subiektywna ocena sędziów kompetentnych: 14 osób normalnie słyszących). Procedurę doboru materiału do testu dokładnie opisują Nielsen i Dau [25]. W teście wyznacza się indywidualne wartości $\mathrm{SRT}_{\mathrm{N}}$.

Wśród prób mierzących zdolność rozumienia zdań w obecności sygnału zakłócającego warto wymienić również Test stuchania $w$ przestrzennym hałasie (ang. The Listening in Spacialized Noise Test, LISN ${ }^{\circledR}$ ) [26]. Celem testu jest ocena umiejętności lokalizacji dźwięku w przestrzeni oraz zdolności wyodrębniania słuchowej figury z tła. W teście zastosowano technikę symulacji warunków panujących w tzw. wolnym polu, ale z wykorzystaniem słuchawek. Celem było stworzenie, możliwie jak najbardziej realistycznego, wrażenia przestrzennego w percepcji dźwięków. Bodźce podawano obuusznie. Prezentowano zdania - dystraktory, nagrane przez różnych mówców obu płci, w tle właściwego materiału (opowiadania napisanego przez znanego australijskiego pisarza). Osoba badana miała określić, czy historyjka była „łatwa do zrozumienia”, „tylko zrozumiała” czy „zbyt trudna do zrozumienia”, wskazując odpowiednią kartę odpowiedzi. Materiał właściwy i rozpraszający był podawany do tego samego lub różnych uszu, jak również mógł być wypowiadany przez tego samego lub różnych spikerów. Dzięki temu możliwe było porównanie poziomu wykonania testu w różnych warunkach eksperymentalnych (np. ta sama lokalizacja, różni mówcy lub różna lokalizacja, różni mówcy). Określano najniższe wartości S/N wyznaczane w ww. sytuacjach. Szczegóły techniczne dotyczące zastosowanej stymulacji oraz procedury pomiaru i obliczania wyników zostały zawarte w pracy Cameron i wsp. (2006) [27].

\section{Mowa filtrowana}

Kolejną kategorią testów mierzących zrozumiałość mowy zniekształconej są zadania zawierające mowę filtrowaną częstotliwościowo. Jak sama nazwa wskazuje, materiał bodźcowy jest w nich sztucznie modyfikowany $\mathrm{z}$ zastosowaniem systemu filtrów przepuszczających niskie lub wysokie częstotliwości w paśmie mowy (od $300 \mathrm{~Hz}$ do $3 \mathrm{kHz}$ ). 
Testy słów filtrowanych pozwalają zrozumieć wkład poszczególnych częstotliwości, z których składa się mowa, w zdolność do odbioru ustnych przekazów [28]. Bornstein i wsp. [28] zaobserwowali, że osoby z prawidłową czułością słuchu uzyskują 70\% poprawnych odpowiedzi, kiedy prezentowane bodźce słowne składają się z częstotliwości od $1500 \mathrm{~Hz}$ do $2100 \mathrm{~Hz}$. Częstotliwości poniżej $1500 \mathrm{~Hz}$ i powyżej $2100 \mathrm{~Hz}$ nie są zatem krytyczne dla rozumienia mowy. Owe punkty odcięcia zależą od spektralnej energii bodźców słownych i mogą być różne dla różnych języków.

Mowa filtrowana została po raz pierwszy użyta jako technika diagnostyczna dla dysfunkcji płata skroniowego [29]. Bocca i wsp. [29] zaobserwowali, że jednouszna prezentacja materiału zmodyfikowanego przy użyciu filtra dolnoprzepustowego powoduje słabsze wykonanie testu różnicowania słów u pacjentów z uszkodzeniem płata skroniowego w uchu kontralateralnym do umiejscowienia lezji. Wykazano, że w wykonanie tego testu są również zaangażowane struktury pnia mózgu. W innym badaniu Matzker i wsp. (1959, za: [28]) niskoczęstotliwościowe pasmo mowy było prezentowane do jednego ucha, a wysokoczęstotliwościowe - do drugiego. Zadanie polegało na połączeniu tych informacji w jedną całość (tzw. obuuszna integracja, ang. binaural fusion). Na podstawie wyników powyższych badań sformułowano ogólne zasady dotyczące przetwarzania sygnału filtrowanego częstotliwościowo, z których najważniejsze są następujące: 1) dla materiału filtrowanego filtrem dolnoprzepustowym: im niższa częstotliwość odcięcia, tym niższy poziom wykonania zadania polegającego na rozpoznawaniu słów, 2) dla bodźców zmodyfikowanych przy użyciu filtra górnoprzepustowego: im wyższa częstotliwość odcięcia, tym słabsze wyniki [28].

Wśród testów mierzących zrozumiałość mowy filtrowanej warto wymienić Mowe filtrowang Ivey (ang. Ivey filtered speech), która wchodzi w skład Baterii testów centralnych Willeford, Test słuchowy Uniwersytetu Północnozachodniego $n r 6$ (ang. Northwestern University Auditory Test No. 6, NU-6) oraz Słowa filtrowane (ang. Filtered Words) z baterii SCAN [30,31]. W pierwszym $\mathrm{z}$ wyżej wymienionych materiał bodźcowy został zmodyfikowany poprzez nałożenie filtra dolnoprzepustowego (częstotliwość odcięcia: $500 \mathrm{~Hz}$ ) i stanowią go dwie listy zawierające po 50 słów. Zasada konstrukcji NU-6 jest podobna do Mowy filtrowanej Ivey, z tym że częstotliwości odcięcia jest więcej (500, 700, 1000 i $1500 \mathrm{~Hz}$ ). Z kolei test z baterii SCAN zawiera jednosylabowe słowa zmodyfikowane przy użyciu filtra dolnoprzepustowego $\mathrm{z}$ częstotliwością odcięcia albo $750 \mathrm{~Hz}$ (wersja dla osób dorosłych), albo $1000 \mathrm{~Hz}$ (wersja dla dzieci). Oznacza to, że częstotliwości niższe od 750 lub $1000 \mathrm{~Hz}$ zostały usunięte $\mathrm{z}$ materiału bodźcowego. Powoduje to efekt „wytłumienia” słów. Test został zaadaptowany do użycia w innych, również nieanglojęzycznych, krajach [32,33]. Przykładowo, Fuente i McPherson (2006) [32] w swoich badaniach stosowali dwie listy zawierające po 25 słów w języku hiszpańskim, które zostały zmodyfikowane częstotliwościowo. Listę 1. tworzył materiał filtrowany dolnoprzepustowo (częstotliwość odcięcia: $500 \mathrm{~Hz}$ ), a Listę 2. - górnoprzepustowo (częstotliwość odcięcia: $3000 \mathrm{~Hz}$ ). Listę 1. podawano do jednego ucha, a Listę 2. - do drugiego.

Poszczególne wersje testów różnią się materiałem oraz parametrami filtracji sygnału. $\mathrm{W}$ testach wykorzystywane są zarówno słowa sensowne, jak i nonsensowne. W jednym $\mathrm{z}$ ostatnich badań [34] sprawdzano wpływ rodzaju bodźców językowych na wykonanie testu filtracji mowy. Prezentowano 80 jednosylabowych słów sensownych i 80 nonsensownych, które nie różniły się pod względem parametrów filtracji. U 30 osób zastosowano bardziej ostry filtr $(2000-500 \mathrm{~Hz})$, a u pozostałych badanych - łagodniejszy (3000-1500 Hz). Dla zakresu: $3000-1750 \mathrm{~Hz}$ poziom wykonania testu dla słów sensownych był znacząco wyższy niż dla nonsensownych. Dla filtracji w przedziale 500-1250 Hz wyniki były lepsze w przypadku ekspozycji słów nonsensownych. Zawartość językowa prezentowanego materiału istotnie poprawiała wykonanie testu tylko w sytuacji, gdy zastosowano filtr powyżej $1500 \mathrm{~Hz}$. Autorzy badania sugerują zatem, że należy ostrożnie interpretować wyniki testów mowy filtrowanej, mając na uwadze, że zdolności językowe mogą na nie znacząco wpływać.

\section{Mowa skompresowana}

Jednym $\mathrm{z}$ aspektów APD są trudności w rozumieniu mowy wypowiadanej w szybkim tempie. Obniżenie poziomu wykonania testów, w których mowa została poddana kompresji czasowej, jest widoczne zwłaszcza u osób starszych [35-37]. W testach mierzących mowę skompresowaną wyznacza się tzw. próg czasowej kompresji (ang. Time-Compression Threshold, TCT), czyli tempo mowy (wyrażone ilością sylab na sekundę), dla którego 50\% prezentowanych słów/zdań jest poprawnie powtórzonych. Osoby starsze zwykle uzyskują wyższe wartości TCT w porównaniu z osobami młodymi [35]. W innym badaniu [38] eksponowano słowa jedno- lub dwusylabowe, oddzielnie do każdego ucha, skompresowane na poziomie $50 \%, 60 \%$ lub $70 \%$. Najbardziej stabilną miarą zrozumiałości mowy przyspieszonej były listy słów z 60-proc. kompresją (średnio: $90 \%$ poprawnych odpowiedzi).

Testy mowy skompresowanej są czułe na wykrywanie rozsianych lezji w obszarze pierwszorzędowej kory słuchowej. Bodźce językowe skompresowane na poziomie $65 \%$ są trudne do zrozumienia dla większości zdrowych osób. Dlatego dla celów klinicznych sugeruje się użycie 45-proc. kompresji [34].

\section{Wpływ wieku}

Wykonanie testów mierzących zrozumiałość mowy w hałasie lub mowy zniekształconej zmienia się z wiekiem. Efekt ten zależy od złożoności prezentowanego materiału. Przykładowo w jednej z pierwszych wersji testu zrozumiałości mowy w hałasie (ang. Speech Perception in Noise Test, SPIN [39]), w której eksponowano zdania, 15-17-latki uzyskiwały lepsze wyniki niż 11-13-latki, w sytuacji gdy sygnał i szum prezentowano na tym samym poziomie intensywności. Podobne wyniki wskazujące, że poziom wykonania testu dopiero w wieku 15-16 lat jest zbliżony do dorosłego, uzyskali także inni autorzy [33]. Z kolei wyniki innego testu, oceniającego zrozumiałość krótkiego opowiadania eksponowanego słuchowo w obecności zdań dystrakcyjnych (ang. The Listening in Spatialized Noise, LISN ${ }^{\circledR}$ ), nie różniły się istotnie u 7-, 8- i 9-latków, przy czym dzieci miały nieznacznie większe trudności w tym zadaniu niż dorośli [26]. Umiejętność zrozumienia pojedynczych słów w hałasie wydaje się być rozwinięta już ok. 6 r.ż. W tym 
wieku poziom wykonania testów rozumienia mowy w hałasie nie odbiega znacząco od wyników uzyskiwanych przez osoby dorosłe [22].

Rozumienie mowy filtrowanej częstotliwościowo nieznacznie poprawia się między 6 a 10 r.ż. [22,31,33], 10-latki radzą sobie w tym zadaniu tak dobrze jak dorośli [22]. W testach mowy przyspieszonej obniżone wyniki uzyskują głównie osoby starsze [35].

\section{Wnioski}

Zdolność do rozpoznawania zniekształconych bodźców słownych jest istotnym aspektem przetwarzania informacji docierających drogą słuchową, dlatego próby oceniające tę umiejętność powinny wchodzić w skład każdej baterii testów czułych na wykrywanie ośrodkowych zaburzeń przetwarzania słuchowego. Miary te stanowią część komercyjnie dostępnych, wystandaryzowanych baterii takich jak SCAN czy MAPA [22,24,30,31].
Przydatność oryginalnych wersji testów opisanych w tej pracy do diagnostyki przesiewowej ośrodkowych procesów przetwarzania słuchowego w Polsce jest znikoma, właśnie z powodu językowego charakteru materiału bodźcowego. Ze względu na udokumentowaną przydatność kliniczną tych testów, a zwłaszcza prób rozumienia mowy prezentowanej w obecności sygnału zakłócającego oraz mowy filtrowanej częstotliwościowo, warto opracować ich polskie wersje z uwzględnieniem specyficznych cech naszego języka. Wymagałoby to współpracy interdyscyplinarnego zespołu specjalistów z dziedziny medycyny, psychoakustyki i języka.

Publikacja powstała $w$ zwiazku $z$ realizacja projektu pn. „Zintegrowany system narzędzi do diagnostyki i telerehabilitacji schorzeń narządów zmysłów (słuchu, wzroku, mowy, równowagi, smaku, powonienia)" INNOSENSE, wspótfinansowanego przez Narodowe Centrum Badań i Rozwoju w ramach Programu STRATEGMED.

\section{Piśmiennictwo:}

1. ASHA. (Central) Auditory Processing Disorders. Working Group on Auditory Processing Disorders, 2005, http://www.asha. org/policy/TR2005-00043/.

2. AAA 2010. American Academy of Audiology Clinical Practice Guidelines Diagnosis, Treatment and Management of Children and Adults with Central Auditory Processing Disorder, 2010, 1-51.

3. Bellis TJ, Bellis JD. Chapter 30 - Central auditory processing disorders in children and adults. Handb Clin Neurol, 2015; 129: 537-56.

4. Palmer AR, Summerfield AQ. Microelectrode and neuroimaging studies of central auditory function. Br. Med. Bull., 2002; 63(1): 95-105.

5. Bishop CW, Miller LM: A multisensory cortical network for understanding speech in noise. J Cogn Neurosci, 2009; 21(9): 1790-804.

6. Wilson RH, Burks C. Use of 35 words for evaluation of hearing loss in signal-to-babble ratio: A clinic protocol. J Rehabil Res Dev, 2005; 42(6): 839-52.

7. Wilson RH, Carnell CS, Cleghorn AL. The Words-in-Noise (WIN) test with multitalker babble and speech-spectrum noise maskers. J Am Acad Audiol, 2007; 18(6): 522-29.

8. Wilson RH, McArdle R. Speech-in-noise measures: Variable versus fixed speech and noise levels. Int J Audiol, 2012; 51(9): 708-12.

9. Wilson RH, Cates WB. A comparison of Two Word-Recognition Tasks in multitalker babble: Speech Recognition in Noise Test (SPRINT) and Words-in-Noise Test (WIN). J Am Acad Audiol, 2008; 19(7): 548-56.

10. Wilson RH, Farmer NM, Gandhi A, Shelburne E, Weaver J. Normative data for the Words-in-Noise Test for 6-to 12-year-old children. J Speech Lang Hear Res, 2010; 53(5): 1111-21.

11. Wilson RH, McArdle R. Intra- and inter-session test, retest reliability of the Words-in-Noise (WIN) test. J Am Acad Audiol, 2007; 18(10): 813-25.

12. Wilson RH, Burks CA, Weakley DG. Word recognition in multitalker babble measured with two psychophysical methods. J Am Acad Audiol, 2005; 16(8): 622-30.
13. Wilson RH, Abrams HB, Pillion AL. A word-recognition task in multitalker babble using a descending presentation mode from $24 \mathrm{~dB}$ to $0 \mathrm{~dB}$ signal to babble. J Rehabil Res Dev, 2003; 40(4): 321-27.

14. Wilson RH, Cates WB. A comparison of Two Word-Recognition Tasks in multitalker babble: Speech Recognition in Noise Test (SPRINT) and Words-in-Noise Test (WIN). J Am Acad Audiol, 2008; 19(7): 548-56.

15. Wilson RH. Clinical experience with the words-in-noise test on 3430 veterans: Comparisons with pure-tone thresholds and word recognition in quiet. J Am Acad Audiol, 2011; 22(7): $405-23$.

16. Keith RW. Development and standardization of SCAN-A: test of auditory processing disorders in adolescents and adults. J Am Acad Audiol, 1995; 6: 286.

17. Keith RW. Development and standardization of SCAN-C test for auditory processing disorders in children. J Am Acad Audiol, 2000; 11(8): 438-45.

18. Dawes P, Bishop DV. The SCAN-C in testing for auditory processing disorder in a sample of British children. Int J Audiol, 2007; 46(12): 780-86.

19. Fuente A, McPherson B. Auditory processing tests for Spanish-speaking adults: An initial study: Pruebas de percepción auditiva para adultos hablantes del español: un estudio inicial. Int J Audiol, 2006; 45(11): 645-59.

20. Iliadou V, Fourakis M, V akalos A, Hawks JW, Kaprinis G. Bi-syllabic, Modern Greek word lists for use in word recognition tests: Listas de palabras bisilábicas del Griego moderno para uso en pruebas de discriminación. Int J Audiol, 2006; 45(2): 74-82.

21. Kedmy M, Topper T, Cohen-Mimran R, Banai K. The development of speech-in-noise perception in Hebrew-speaking school-age children. J Basic Clin Physiol Pharmacol, 2013; 24(3): 185-89.

22. Stollman MH, van Velzen EC, Simkens HM, Snik AF, van den Broek P. Development of auditory processing in 6-12-year-old children: a longitudinal study. Int J Audiol, 2004; 43(1): 34-44. 
23. Neijenhuis K, Snik A, Priester G, van Kordenoordt S, van den Broek P. „Age effects and normative data on a Dutch test battery for auditory processing disorders: Efectos de la edad y datos normativos de una bateria de pruebas holandesa para evaluar problemas de procesamiento auditivo. Int J Audiol, 2002; 41(6): 334-46.

24. Schow RL, Seikel JA, Brockett JE, Whitaker MM. Multiple Auditory Processing Assessment (MAPA). Test Manual. Idaho State University, 2007; 1-56.

25. Nielsen JB, Dau T. Development of a Danish speech intelligibility test. Int J Audiol, 2009; 48(10): 729-41.

26. Cameron S, Dillon H, Newall P. The Listening in Spatialized Noise test: Normative data for children: La prueba de audición en ruido espacializado: datos normativos para niños. Int J Audiol, 2006; 45(2): 99-108.

27. Cameron S, Dillon H, Newall P. Development and evaluation of the listening in spatialized noise test. Ear Hear, 2006; 27(1): $30-42$.

28. Bornstein SP, Wilson RH, Cambron NK. Low-and high-pass filtered Northwestern University Auditory Test No. 6 for monaural and binaural evaluation. J Am Acad Audiol, 1994; 5: 259.

29. Avilala VKY, Prabhu P, Barman A. The effect of filtered speech on speech identification scores of young normal hearing adults. J India Inst Speech Hear, 2010; 29(1).

30. Keith RW. Development and standardization of SCAN-A: test of auditory processing disorders in adolescents and adults. J Am Acad Audiol, 1995; 6: 286-86.

31. Keith RW. Development and standardization of SCAN-C test for auditory processing disorders in children. J Am Acad Audiol, 2000; 11(8): 438-45.
32. Fuente A, McPherson B. Auditory processing tests for Spanish-speaking adults: An initial study: Pruebas de percepción auditiva para adultos hablantes del español: un estudio inicial. Int J Audiol, 2006; 45(11): 645-59.

33. Neijenhuis K, Snik A, Priester G, van Kordenoordt S, van den Broek P. Age effects and normative data on a Dutch test battery for auditory processing disorders: Efectos de la edad y datos normativos de una bateria de pruebas holandesa para evaluar problemas de procesamiento auditivo. Int J Audiol, 2002; 41(6): 334-46.

34. Arnott W, Goli T, Bradley A, Smith A, Wilson W. The Filtered Words Test and the influence of lexicality. J Speech Lang Hear Res, 2014; 57(5): 1722.

35. Versfeld NJ, Dreschler WA. The relationship between the intelligibility of time-compressed speech and speech in noise in young and elderly listeners. J Acoust Soc Am, 2002; 111(1): 401.

36. Jafari Z, Omidvar S, Jafarloo F. Effects of ageing on speed and temporal resolution of speech stimuli in older adults. Med J Islam Repub Iran, 2013; 27(4): 195-203.

37. Gordon-Salant S, Fitzgibbons PJ. Sources of age-related recognition difficulty for time-compressed speech. J Speech Lang Hear Res, 2001; 44(4): 709-19.

38. Rabelo CM, Schochat E. Time-compressed speech test in Brazilian Portuguese. Clinics, 2007; 62(3): 261-72.

39. Kalikow DN, Stevens KN, Elliott LL. Development of a test of speech intelligibility in noise using sentence materials with controlled word predictability. J Acoust Soc Am, 1977; 61(5): 1337-51. 